\title{
Cryptic Scale Infestations on Cycas revoluta Facilitate Scale Invasions
}

\author{
Thomas E. Marler ${ }^{1}$ and Aubrey Moore \\ Western Pacific Tropical Research Center, College of Natural and Applied \\ Sciences, University of Guam, UOG Station, Mangilao, Guam 96923
}

Additional index words. Aulacaspis yasumatsui, cycad, invasive species, insect invasions

\begin{abstract}
The cycad aulacaspis scale (Aulacaspis yasumatsui Takagi) has invaded numerous geographic regions in the past 15 years. The sequential invasions have decimated many $C y c a s$ nursery and landscape industries and threatened $C$. micronesica K.D. Hill and $C$. taitungensis C.F. Shen, K.D. Hill, C.H. Tsou and C.J. Chen within their native habitats. The majority of the international cycad trade is dominated by Cycas revoluta Thunberg. We removed dense tomentum that characterizes $C$. revoluta cataphylls and excised intact leaf bases from stems of landscape $C$. revoluta plants to expose hidden surfaces. Additionally, we removed the root system from containers on nursery plants to reveal enclosed roots. All three organs were infested with cycad aulacaspis scale on tissue surfaces that cannot be detected during thorough visual inspection of intact plants. These unique concealed infestations allow this species to vector scale insects in a cryptic manner on cataphyll, stem, and root surfaces. This information lends support for a policy of strict prohibition of imported $C$. revoluta plants from countries known to have cycad aulacaspis scale infestations.
\end{abstract}

Cycads are an ancient lineage of plants routinely referred to as "living fossils" (Norstog and Nicholls, 1997; Seward, 1917). The genus Cycas exhibits the most primitive features from among all cycad genera, and these charismatic plants possess ethnobiological, evolutionary, ecological, and horticultural characteristics that attract the interest of biologists (Brenner et al., 2003; Norstog and Nicholls, 1997).

The cycad aulacaspis scale (CAS) was described by Takagi (1977). It is considered a minor pest of Cycas plants within its native Asian range (IUCN SSC, 2006a) presumably as a result of natural biological control organisms (e.g., Tang et al., 1997). The accidental introduction of CAS to Florida in the 1990s (Howard et al., 1999) initiated subsequent invasions of the pest throughout several other states within the United States and other countries (IUCN SSC, 2006b; Marler and Muniappan, 2006). These events have threatened regional and international horticulture operations and natural populations of several Cycas species. For example, the International Union for Conservation of Nature has listed C. taitungensis as vulnerable (Hill, 2003) and C. micronesica as endangered (Marler et al., 2006) as a result of declines in populations as a direct result of CAS invasions into Taiwan and Guam, respectively (IUCN SSC, 2006b).

Received for publication 28 Dec. 2009. Accepted for publication 12 Feb. 2010.

Funding provided by United States Forest Service Forest Health Management Program, Region 5, and by the United States Department of Agriculture's Animal and Plant Health Inspection Service (APHIS); information does not necessarily express APHIS' views.

${ }^{1}$ To whom reprint requests should be addressed; e-mail tmarler@uguam.uog.edu.
The most popular Cycas species in the international horticulture industry is Cycas revoluta (Norstog and Nicholls, 1997). It is widely represented in commercial and residential landscapes (Fig. 1A), as containerized specimen plants (Fig. 1B), in bonsai applications, and in the floriculture industry as greenery. According to Convention on International Trade in Endangered Species data, the number of $C$. revoluta plants crossing international borders in legal trade from 1983 until 1999 greatly exceeded that of any other cycad species (Donaldson et al., 2003). These legal export-import events were theoretically accompanied by inspections by qualified agents, sometimes at both locations. In this article, we present three morphological characteristics of $C$. revoluta indicating that detection of CAS infestations by thorough inspection of an intact plant is not practically achievable. An increased appreciation for this unfortunate characteristic may prevent the horticulture industry from fostering further invasions of this destructive pest.

\section{Materials and Methods}

Cycas revoluta plants on the island of Guam (long. $13.49^{\circ} \mathrm{N}$; lat. $144.80^{\circ} \mathrm{E}$ ) were used to determine if CAS is capable of infesting hidden tissue surfaces on various organs. The CAS invasion of Guam was initially detected in 2003 where infested C. revoluta plants were identified in hotel landscapes in the main tourist district of the island. Natural habitats of the native $C$. micronesica throughout the island were rapidly invaded thereafter. The "scale destroyer" Rhyzobius lophanthae Blaisdell (Coleoptera: Coccinellidae) was introduced and released after quarantine in Feb. 2005 (Moore et al., 2005). This predator promptly established and suspended the mortality rate of $C$. revoluta and $C$. micronesica plants. This history has produced an environment on Guam that is representative of many contemporary $C$. revoluta horticulture production areas. Cycad aulacaspis scale pressure is unrelenting and minor infestations are widespread, but heavy infestations of visible plant surfaces are rare as a result of biological or chemical control.

We used three methods in Oct. 2009 to uncover three tissue surfaces that are not visible on an intact plant: 1) Cycas stem apices are protected by modified leaves called cataphylls (Norstog and Nicholls, 1997). Cataphyll morphology differs among species but is highly stable within a species. Cycas revoluta cataphylls are adorned by an unusually thick tuft of tomentum (Fig. 1C). We used water pressure to gently remove tomentum on the cataphylls of 10 landscape plants ranging from 0.4 to $1.2 \mathrm{~m}$ in height to expose cataphyll surfaces; 2) the surface of an intact $C$. revoluta stem appears rough as a result of retained bases of former leaves (Fig. 1G). Inspection of the surface of this intact stem does not divulge the presence of cryptic cavities. A longitudinal section of a C. revoluta stem, however, reveals live parenchyma extending into the leaf bases and hidden cavities separating the leaf bases of this species (Fig. 1H). We used a knife to remove 10 leaf bases from each of the plants described. The hidden surfaces of these leaf bases were inspected for CAS; and 3) roots of plants shipped in containers are not visible. To inspect $C$. revoluta roots, the root mass of each of six plants growing in 5.1-L containers at the University of Guam was removed by turning each container upside down and gently slipping the container away from the roots. No medium was removed, and all roots made visible by removal of the container were inspected for CAS infestations. The region of highest CAS density during the inspections was identified, and the density of CAS within $101 \times 1-\mathrm{cm}$ squares in these areas was measured on each of the three organs for each plant with a Carson MicroMax portable microscope (Forestry Suppliers, Inc., Jackson, MS). Only nonmobile adult individuals were counted. Additionally, the body size of five CAS crawlers was measured to expand the discussion of plant, herbivore, and predator relations.

\section{Results and Discussion}

Thorough visual inspection of Cycas revoluta cataphylls before removal of tomentum revealed no apparent presence of CAS (Fig. 1C). After removal of tomentum, heavy CAS density was observed on underlying cataphyll surfaces of all 10 plants (Fig. 1D-E). The heaviest infestations ranged from 8 to 14 individuals per $\mathrm{cm}^{2}$. These high-density infestations were comprised of $68 \%$ female and $32 \%$ male individuals.

Comprehensive inspection of intact Cycas revoluta stem surfaces revealed no apparent CAS. The detached leaf bases from eight of 10 plants were also free of apparent CAS infestations. However, detached leaf bases from two of the experimental plants revealed 

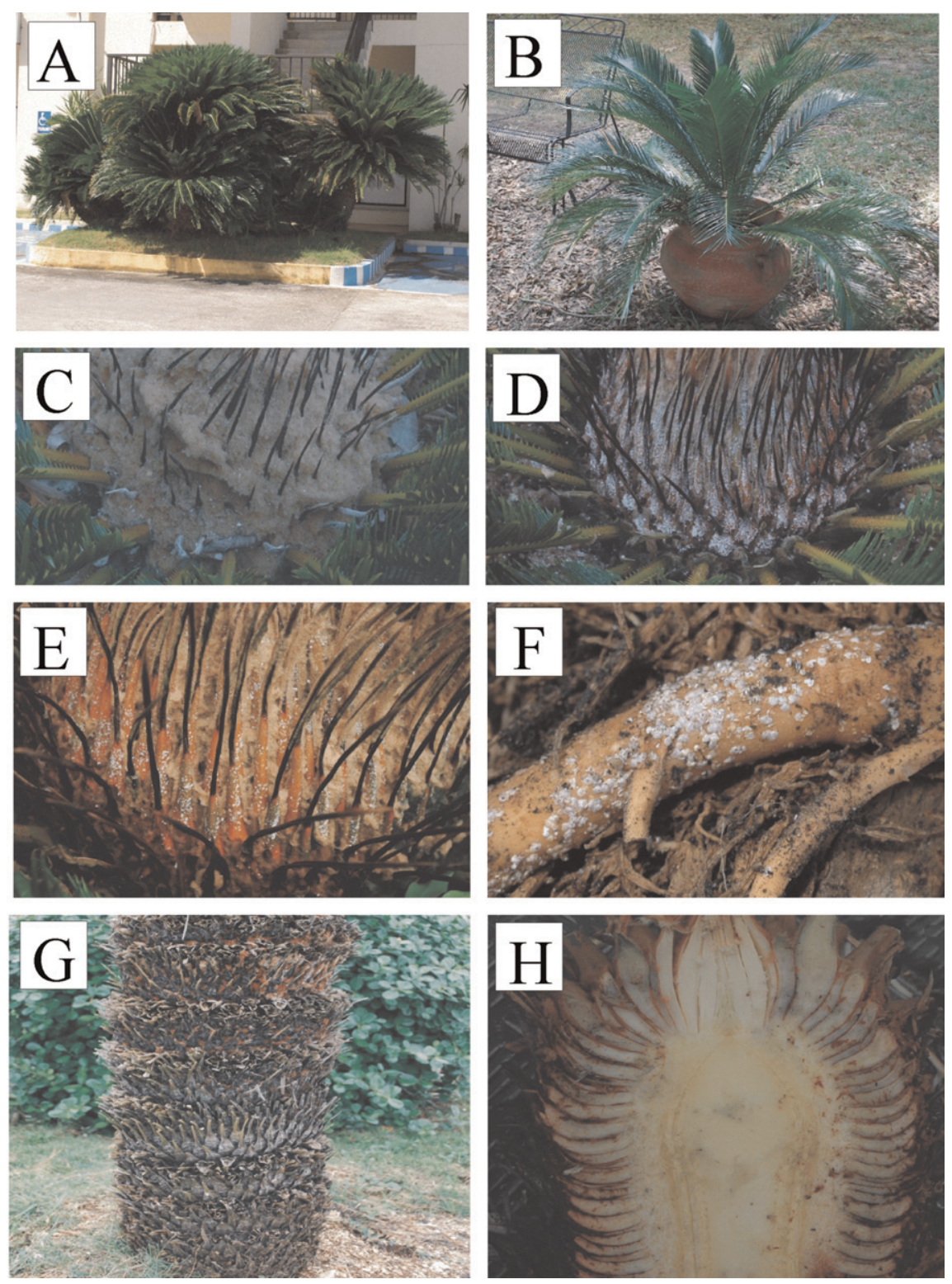

Fig. 1. (A) Cycas revoluta plants are used in the landscape industry such as this specimen on the island of Saipan (long. $15.15^{\circ} \mathrm{N}$, lat. $145.70^{\circ} \mathrm{E}$ ). (B) C. revoluta is used in horticulture as container-grown plants such as this specimen displayed in Mississippi (long. $32.48^{\circ} \mathrm{N}$, lat. $89.48^{\circ} \mathrm{W}$ ). (C) Phenotype of C. revoluta cataphyll complex in a natural state. (D) Phenotype of the same cataphylls after removal of tomentum. (E) Closeup of Aulacaspis yasumatsui infesting the hidden cataphyll surfaces after remova of tomentum. (F) Roots of a container-grown C. revoluta plant showing A. yasumatsui infestation. (G) Phenotype of the surface of an intact C. revoluta stem. (H) Longitudinal section of a C. revoluta stem revealing hidden cavities between retained live leaf bases.

CAS infestations on the adaxial surface. Three of 10 leaf bases on one tree and six of 10 on the second tree supported low-density CAS that ranged from one to three individuals per $\mathrm{cm}^{2}$. These hidden insects were mostly female with a ratio of $74 \%$ female to $26 \%$ male.

Visual inspection of root surfaces as seen through the drainage holes in Cycas revoluta containerized plants revealed no visible CAS on root surfaces. However, after removal of the root mass from each container, roots that developed near the drainage holes within the 20 - to $45-\mathrm{mm}$ diameter class range were heavily infested with CAS (Fig. 1F). Highest density infestations ranged from 9 to 21 individuals per $\mathrm{cm}^{2}$. These root infestations were $52 \%$ female and $48 \%$ male.

The CAS infestations on hidden cataphyll, stem, and root surfaces apparently develop as a result of minute CAS crawler size that allows the juvenile animal to maneuver the labyrinth of tomentum on cataphylls, cryptic cavities of leaf bases, and hidden pores of container medium to access plant surfaces suitable for colonizing. Body size of CAS crawlers ranged from 225 to $248 \mu \mathrm{m}$ in length. In contrast, $R$. lophanthae adults range in size from 2.4 to $2.5 \mathrm{~mm}$ in length (Stathas et al., 2002). Under the conditions of Guam with chronic CAS crawler pressure and reasonable predator control, these hidden plant surfaces become refu- gia providing protection for CAS persistence because the predators are too large to access the same microsites. Removal of biological control by transporting these same plants to new CAS-free locations allows these hidden refugia to become prolific CAS brooding facilities.

The IUCN SSC Cycad Specialist Group has recommended three possible quarantine measures for the transport of Cycas plants from infested countries (IUCN SSC, 2006a). These include: 1) prohibiting entry of host cycad plants; 2) mandatory insecticide treatment as a condition of entry; and 3) "close inspection of host plants" for infestations with subsequent insecticide treatment when infestations are found. Our results illuminate the application of these recommendations by revealing that the unique morphology of $C$. revoluta cataphylls and stems offer hidden surfaces for secretive CAS infestations. Furthermore, root surfaces hidden within containers of nursery plants harbor high-density CAS infestations. Therefore, the use of close inspection as a condition of entry into CASfree geographic regions cannot be endorsed as a means of thwarting new invasions. Furthermore, the evaluation of efficacy of insecticide treatment would be arduous considering the hidden surfaces that would need to be inspected. A strict prohibition of $C$. revoluta plant translocation from infested countries into CAS-free countries is supported by these observations. This approach would also be far less expensive ecologically and monetarily than dealing with invasions of yet more locations.

\section{Literature Cited}

Brenner, E.D., D.W. Stevenson, R.W. McCombie, M.S. Katari, S.A. Rudd, K.F. Mayer, P.M Palenchar, S.J. Runko, R.W. Twigg, G. Dai, R.A. Martienssen, P.N. Benfey, and G.M. Coruzzi. 2003. Expressed sequence tag analysis in Cycas, the most primitive living seed plant. Genome Biol. 4:R78. 10 Feb. 2010. $<$ http://genomebiology.com/2003/4/12/R78>.

Donaldson, J.S., B. Dehgan, A.P. Vovides, and W. Tang. 2003. Cycads in trade and sustainable use of cycad populations, p. 39-47. In: Donaldson, J.S. (ed.). Cycads status survey and conservation action plan. IUCN The World Conservation Union, Gland, Switzerland.

Hill, K.D. 2003. Cycas taitungensis. In: IUCN 2009. IUCN red list of threatened species. Version 2009.2. 10 Feb. 2010. <http://www. iucnredlist.org $>$.

Howard, F.W., A. Hamon, M. McLaughlin, T. Weissling, and S.-L. Yang. 1999. Aucalaspis yasumatsui (Hemiptera: Sternorrhyncha: Diaspididae), a scale insect pest of cycads recently introduced into Florida. Fla. Entomol. 82:1427.

IUCN SSC. 2006a. Pest alert. Cycad aulacaspis scale. 10 Feb. 2010. <http://www.cycadsg.org publications/CAS/Cycad-Aulacaspis-Scale-PestAlert.pdf $>$

IUCN SSC. 2006b. Report and recommendations on cycad aulacaspis scale, Aulacaspis yasumatsui Takagi (Hemiptera: Diaspididae). 10 Feb. 2010. <http://www.cycadsg.org/publications CAS/CSG-Report-on-Cycad-Aulacaspis-Scale. pdf $>$. 
Marler, T., J. Haynes, and A. Lindström. 2006. Cycas micronesica. In: IUCN 2009. IUCN red list of threatened species. Version 2009.2. 24 Dec. 2009. <http://www.iucnredlist.org>.

Marler, T.E. and R. Muniappan. 2006. Pests of Cycas micronesica leaf, stem, and male reproductive tissues with notes on current threat status. Micronesica 39:1-9.

Moore, A., T.E. Marler, R. Miller, and R. Muniappan. 2005. Biological control of cycad aulacaspis scale on Guam. The Cycad Newsletter 28: 6-8.

Norstog, K.J. and T.J. Nicholls. 1997. The biology of the cycads. Cornell University Press, Ithaca, NY.

Seward, A.C. 1917. Fossil plants. Vol. III. Cambridge Univ. Press, London, UK.

Stathas, G.J., P.A. Eliopoulos, D.C. Kontodimas, and D.T. Siamos. 2002. Adult morphology and life cycle under constant temperatures of the predator Rhyzobius lophanthae Blaisdell (Col., Coccinellidae). J. Pest Sci. 75:105-109.

Takagi, S. 1977. A new species of Aulacaspis associated with a cycad in Thailand (Homoptera: Cocoidea). Insecta Matsumurana New Series 11:63-72.

Tang, W., S.-L. Yang, and P. Vatcharakorn. 1997. Cycads of Thailand. Nong Nooch Tropical Garden and the Cycad Conservation Company, Bangkok, Thailand. 